\title{
Glycemic index and glycemic load of tropical fruits and the potential risk for chronic diseases
}

\author{
Tatiana Uchôa PASSOS ${ }^{1 \star}$, Helena Alves de Carvalho SAMPAIO ${ }^{1}$, Maria Olganê Dantas SABRY ${ }^{1}$,

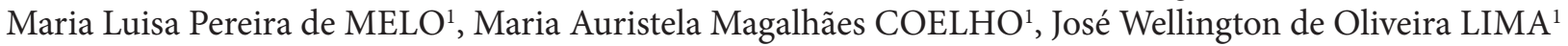

\begin{abstract}
The objective was to determine the glycemic index and glycemic load of tropical fruits and the potential risk for chronic diseases. Nine fruits were investigated: coconut water (for the purpose of this study, coconut water was classified as a "fruit"), guava, tamarind, passion fruit, custard apple, hog plum, cashew, sapodilla, and soursop. The GI and GL were determined according to the Food and Agriculture Organization protocol. The GL was calculated taking into consideration intake recommendation guidelines; $77.8 \%$ of the fruits had low GI although significant oscillations were observed in some graphs, which may indicate potential risks of disease. Coconut water and custard apple had a moderate GI, and all fruits had low GL. The fruits evaluated are healthy and can be consumed following the daily recommended amount. However, caution is recommended with fruits causing early glycemic peak and the fruits with moderated GI (coconut water and custard apple).
\end{abstract}

Keywords: glycemic response; fruits; dietary assessment; chronic diseases.

\section{Introduction}

Chronic non-communicable diseases (CNDs) are increasingly prevalent worldwide causing premature deaths due to changes in diet and lifestyle. Thus, various strategies for prevention and control have been developed in order to stop or delay the spread of these diseases (American Diabetes Association, 2013; Salehi et al., 2012; Salgado et al., 2010).

Three decades ago, the concept of a dietary Glycemic Index (GI) came under discussion as a factor that should be controlled to prevent chronic diseases. This concept was first proposed in 1981 by scientists led by Dr. David Jenkins, University of Toronto, Canada (Jenkins et al., 1981).

The GI of foods is a categorization based on the effect of the content and type of carbohydrates of a food on blood glucose (Brand-Miller et al., 2014; Passos, 2012).

An expert group convened by the Food and Agriculture Organization/World Health Organization (Food and Agriculture Organization \& World Health Organization, 1998) defined GI as the area under the glucose response curve after ingestion of $50 \mathrm{~g}$ of carbohydrates of a test food expressed as a response percentage to the same amount of carbohydrate from a standard food, in the same individual. The standard food is glucose or white bread (Brand-Miller et al., 2014; Food and Agriculture Organization \& World Health Organization, 1998).

In addition to the glycemic index, the amount of carbohydrate in a food is also considered an important determinant of glucose tolerance on fasting and the postprandial glycemic response. Thus, there is another indicator, the glycemic load (GL) of a food, which can be calculated as its carbohydrate content $(\mathrm{g})$ multiplied by the food's GI and divided by 100 , and it is, therefore, a measure that involves the quantity and quality (GI) of dietary carbohydrate (American Diabetes Association, 2013; Danone Vitapole/FAO, 2001).

These two concepts show that both indicators should be determined when assessing how healthy or unhealthy the feeding patterns of a population are.

The GI and GL of meals and daily consumption can be calculated based on the GI and GL values of foods using tables and standardized calculation procedures available (Food and Agriculture Organization \& World Health Organization, 1998; Wolever et al., 2003). These tables are updated whenever new GI and GL values are established for different foods, such as those proposed by Brand-Miller et al. (2014) and Sydney University Glycemic Index Research Service (The University of Sydney, 2001). Among the foods listed in these tables are fruits from different places of origin. There are several studies that address native or cultivated fruits grown in Europe, North America, Oceania, Africa, and Asia. However, there are few studies on fruits native to South America (Almeida et al., 2009), and there are no South American fruits listed in these tables or reported in the recent literature, and they have not been mentioned in recent publications (Brand-Miller et al., 2014). Brazil, a country located in South America, has a wide variety of fruits, but many of these fruits have not yet been included in international tables of glycemic index and glycemic load values (Almeida et al., 2009). 
Fruits deserve special consideration when evaluating safe food consumption because they are included in international guidelines for a healthy diet, as shown in the Dietary Guidelines for Americans (U.S. Department of Agriculture, 2010), in which their daily intake is recommended consumption and they can have a positive impact on the glycemic and cholesterol control and can help reduce the risk of coronary heart disease (Jenkins et al., 2011; Salehi et al., 2012; Balisteiro et al., 2013).

Thus, the fruits with the most suitable composition for consumption should be identified. In general, their recommended intake is based on their concentration of vitamins, minerals, and fiber, whilst little attention has been given to their glycemic effect. Recent publications have discussed other potential benefits of fruit intake (Augustin, 2010; Ballali \& Lanciai, 2012; U.S. Department of Agriculture, 2010; Jenkins et al., 2011; Balisteiro et al., 2013).

The objective of this study is to identify the fruits that are part of the usual diet of certain population groups, to determine their glycemic index and glycemic load, and to assess the potential health risks associated with these two indicators.

\section{Materials and methods}

The present study was conducted at Nutrindo - Laboratory of Nutrition and Chronic Diseases, of the State University of Ceará (UECE). It was approved by the Ethics Committee of Ceará State University - FR 3079667 - (Appendix A), and the individuals who agreed to participate in the study were required to sign a consent form.

\subsection{Identification of fruits with unknown GI}

The laboratory researchers conducted an initial search of research databases for articles published over the past 10 years by at the. These databases contain information on the usual intake of different population groups: children, adolescents, adults, elderly, healthy pregnant women, adults with psychiatric disorders, and adults and seniors with chronic diseases, totaling 1,830 people. Data on fruit intake were collected using questionnaires applied to these specific groups of people, of which 148 different items were identified.

The GI and the GL of the fruits were taken from international tables (Brand-Miller et al., 2014; Brand-Miller et al., 2013). It was found that 10 of the fruits found in the aforementioned database were not included in any of these tables, namely Barbados cherry (Malpighia emarginata), coconut water (for the purpose of this study, coconut water was classified as a fruit) (Cocos nucifera), custard apple (Annona squamosa), hog plum (Spondias lutea), cashew (Anacardium occidentale), guava (Psidium guajava), soursop (Annona muricata), passion fruit (Passiflora sp), sapodilla (Manilkara zapota), and tamarind (Tamarindus indica).

\subsection{Determination of the GI and GL of the fruits identified}

The sample was initially composed of 21 volunteers, students of the university where the present study was conducted, who received a description of the research procedures in visits to their classroom. This number was defined according to two recommendations of the joint FAO/WHO Expert Consultation
(Food and Agriculture Organization \& World Health Organization, 1998): 1) each volunteer may perform up to six glycemic response measurements: 3 after consumption of the standard food (glucose) and one measurement for each food to be tested with a maximum of three foods/person, 2); each food should be tested by a minimum of 6 persons.

According to the FAO/WHO Expert Consultation protocol (Food and Agriculture Organization \& World Health Organization, 1998), the quantity of the standard food and test food should ensure the availability of $50 \mathrm{~g}$ of glycemic carbohydrate (carbohydrates minus fiber). Therefore, the carbohydrate and fibers of each of the ten fruits were determined using the Professional DietWin 2.0 software

The content of carbohydrates, fiber, and glycemic carbohydrates per $100 \mathrm{~g}$ of each fruit is described in Table 1.

The total amount of Barbados cherry was $1872.7 \mathrm{~g}$; therefore, this fruit was excluded from this study to prevent potential operational infeasibility. Consequently, the final volunteer sample was composed of 18 people.

The fruit portions were weighed on a Nutri subtype Plenna digital balance that offers a weighing capacity of $2000 \mathrm{~g}$ and $1 \mathrm{~g}$ graduation.

All procedures for measuring the glycemic response followed the FAO/WHO Expert Consultation Protocol (Food and Agriculture Organization \& World Health Organization, 1998). The area under the curve was calculated as the incremental area under the response curve of glucose. This can be calculated geometrically by applying the trapezoidal rule. It should be noted that when a blood glucose value falls below the base line, the area between this point and the fasting level is not included in the calculation; thus, only the areas above the fasting level are included.

After calculation, the glycemic index was categorized as low, medium, or high based on the classification of Brand-Miller et al. (2003), where low GI $\leq 55$, moderate GI 56-69, and high GI $\geq 70$. The fruits with low-GI were considered healthy.

The glucose load was also calculated as the fruit's carbohydrate content (g) multiplied by the food's GI and divided by 100 , as

Table 1. Content of carbohydrates and fiber in $100 \mathrm{~g}$ of the fruits used in this study.

\begin{tabular}{lcc}
\hline \multicolumn{1}{c}{ Fruit } & Carbohydrate $(\mathrm{g})$ & Fiber $(\mathrm{g})$ \\
\hline Barbados cherry & 5.00 & 2.33 \\
Coconut water & 5.30 & 0.10 \\
Custard Apple & 12.06 & 2.89 \\
Hog plum & 13.80 & 1.00 \\
Cashew & 11.60 & 1.5 \\
Guava & 17.30 & 5.30 \\
Soursop & 14.90 & 1.10 \\
Passion fruit & 21.20 & 0.70 \\
Sapodilla & 25.90 & 9.90 \\
Tamarind & 71.80 & 3.00 \\
\hline
\end{tabular}

* Source: Brazilian Table of Food Composition (Universidade Estadual de Campinas, 2006). 
proposed by Burani (2006). The Brazilian dietary guidelines, which defines one portion of a fruit as the amount that contains 70 calories (Brasil, 2006), were used to calculate the portion of fruits to be used. Different studies available in the literature were reviewed to define the portion of each fruit (Brasil, 2006; Instituto Brasileiro de Geografia e Estatística, 2011; Pacheco, 2006). The GL of each fruit was categorized as low (values less than or equal to 10), moderate (values between11-19), or high, (values greater than or equal to 20), (Burani, 2006).

Table 2 shows the nine fruits that were evaluated and the respective portion used to calculate the GI and GL.

\section{Results}

Graphs 1-9 show the average blood glucose levels obtained with the measurement of diluted glucose (3 measurements) and the measurement of the fruit tested.

\section{Discussion}

The methodological aspects of GI in terms of its determination have been widely discussed. The wide variability between GI values reported by different laboratories can be food-related (digestibility and starch structure, among others) or it can be caused due to methods such as the procedures used to collect blood samples and measure blood glucose, or it can be associated with demographic characteristics and ethnic origin of the subjects (Wolever et al., 2003).

Wolever (2004) compared different protocols to determine the glycemic index, and they suggested the use of the recommendations of the FAO/WHO Expert Consultation protocol (Food and Agriculture Organization \& World Health Organization, 1998), which was adopted in the present study. This protocol is a recommended standard to determine capillary blood glucose levels, and each food was evaluated in six subjects to improve the reliability of the method (Wolever et al., 2003).

Table 2. Portions of selected fruits containing $50 \mathrm{~g}$ glycemic carbohydrate used to calculate the glycemic index (GI) and portion $(\mathrm{g} / \mathrm{mL})$ used to calculate the glycemic load (GL).

\begin{tabular}{lcc}
\hline \multicolumn{1}{c}{ Fruit } & $\begin{array}{c}\text { Portion used to } \\
\text { determine GI }\end{array}$ & $\begin{array}{c}\text { Portion used }(\mathrm{g} / \mathrm{mL}) \text { to } \\
\text { calculate the GL }\end{array}$ \\
\hline Coconut Water & 961.5 & $200.0^{\mathrm{b}}$ \\
Custard Apple & 545.3 & $75.0^{\mathrm{b}}$ \\
Hogs Plum & 390.6 & $70.0^{\mathrm{b}}$ \\
Cashew & 495.0 & $147.0^{-0}$ \\
Guava & 416.7 & $95.0^{\mathrm{c}}$ \\
Soursop & 362.3 & $75.0^{\mathrm{c}}$ \\
Passion fruit & 243.9 & $94.0^{\mathrm{b}}$ \\
Sapodilla & 312.5 & $70.0^{\mathrm{b}}$ \\
Tamarind & 72.7 & $35.0^{\mathrm{b}}$ \\
\hline
\end{tabular}

a Recommended amount according to the Food Guide for the Brazilian population (2006), brecommended amount according to Pacheco (2006), with standard caloric equivalent to that in the Food Guide for the Brazilian population (2006), 'recommended amount according to the Consumer Expenditure Survey (Instituto Brasileiro de Geografia e Estatística, 2011).
Wolever et al. (2003) found variations in the glycemic responses of the same food between the areas of the gliycemic curves after glucose ingestion (standard food) in different individuals and in the same individuals. These variations were also observed in the present study. In the glucose tests, some subjects showed greater increase in the level of blood glucose after intake of certain fruits. In other subjects, the glucose level reached peaks greater than $200 \mathrm{mg} / \mathrm{dL}$ within first 45 minutes after ingestion of the glucose solution, representing an increase of more than $100 \%$ compared with their fasting blood glucose level. The same increase was not observed in the same subjects in the other tests conducted with the glucose solution.

The graphs (Figures 1-9) show that some fruits have a high initial peak of glucose level (15 min), followed by a gradual reduction in blood glucose. This was observed for the coconut water (Figure 1), custard apple (Figure 2), cashew (Figure 4), soursop (Figure 6), and sapodilla (Figure 8). However, as for the cashew, the initial peak was higher than that of the other fruits and even higher than that obtained with the glucose level curves. With regard to custard apple, the normalization of blood glucose values was a little slower than that of cashew.

The early glucose level peak observed in these fruits can be considered a promising result in terms of their recommended intake for patients who have a metabolic syndrome or those who are obese and have diabetes, for example. This is due to the fact that blood glucose level glucose levels can vary widely in diabetic patients, and those who are obese have a strong tendency to develop insulin resistance due to hormone activity, such as leptin. This hormone can begin a chain reaction in the fasting glucose levels or significant insulin sensitivity reduction (Mahan \& Escott-Stump, 2010). Accordingly, the ingestion of large amounts of the fruits tested could induce a major imbalance, especially those with higher early peak, such as cashew fruit. This fruit, which is seasonal and is available almost year round, can be a risk to patients with the diseases mentioned above or even cause these diseases in people who have genetic susceptibility to them.

With regard to custard apple, in addition to its early initial peak, the fact that glucose level normalization is slow makes this fruit a bad choice for patients with high fasting glucose level. The consumption of the custard apple, besides rapidly raising glucose levels, makes glucose level normalization more difficult. This is especially true for individuals with reduced glucose metabolism.

Analyzing the glycemic responses of the hog plum (Figure 3), guava (Figure 5), passion fruit (Figure 7), and tamarind (Figure 9), it was observed that the glucose levels are not very high and remain constant over time, showing that these fruits have low effect on blood glucose levels. Tamarind has the initial peak later, at 30 minutes. Thus, these fruits can be the best option for patients with unregulated glucose levels since they did not have high or early peaks and the blood glucose level remained stable without major peaks or variations contributing to low effect on blood glucose levels.

The amount of fruit required was a negative factor in this study. Although the subjects were allowed to select the fruit 

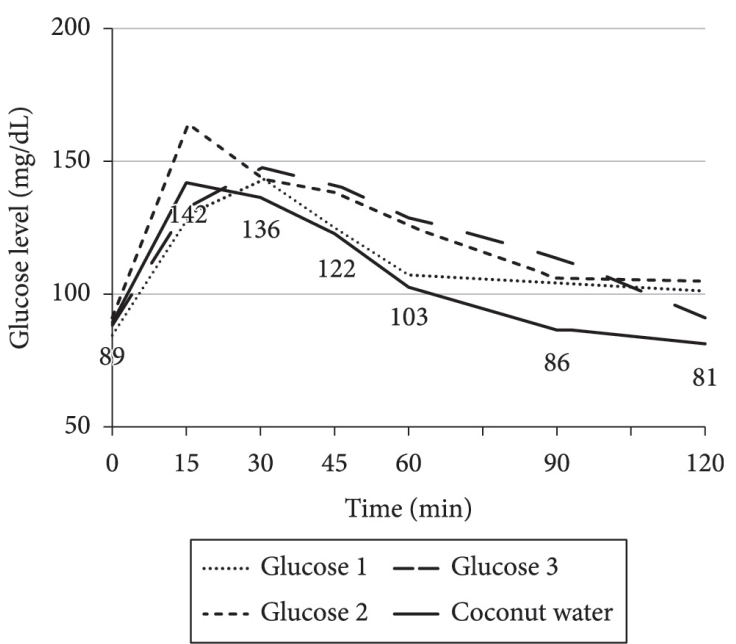

Figure 1. Average glucose levels based on the intake of coconut water by healthy subjects $(n=6)$.

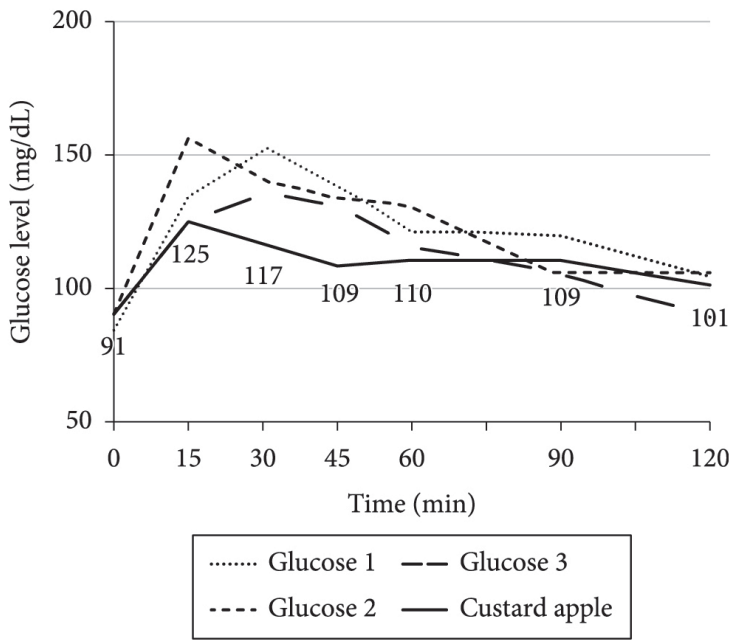

Figure 2. Average glucose levels based on the intake of custard apple by healthy subjects $(n=6)$.

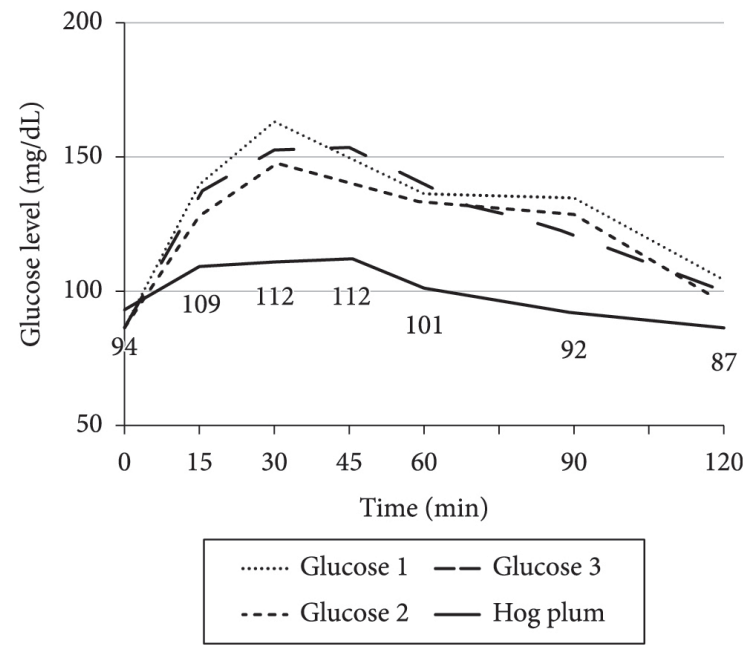

Figure 3. Average glucose levels based on the intake of hog plum by healthy subjects $(n=6)$.
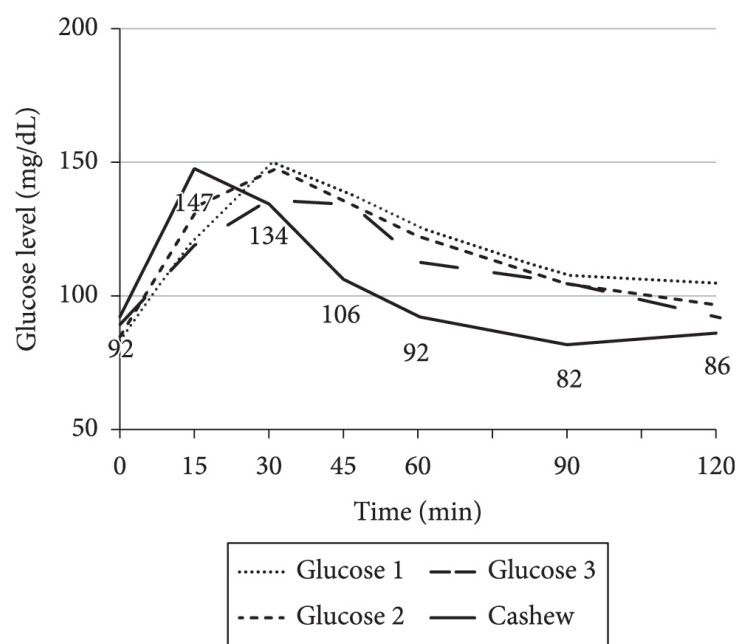

Figure 4. Average glucose levels based on the intake of cashew by healthy subjects $(n=6)$.

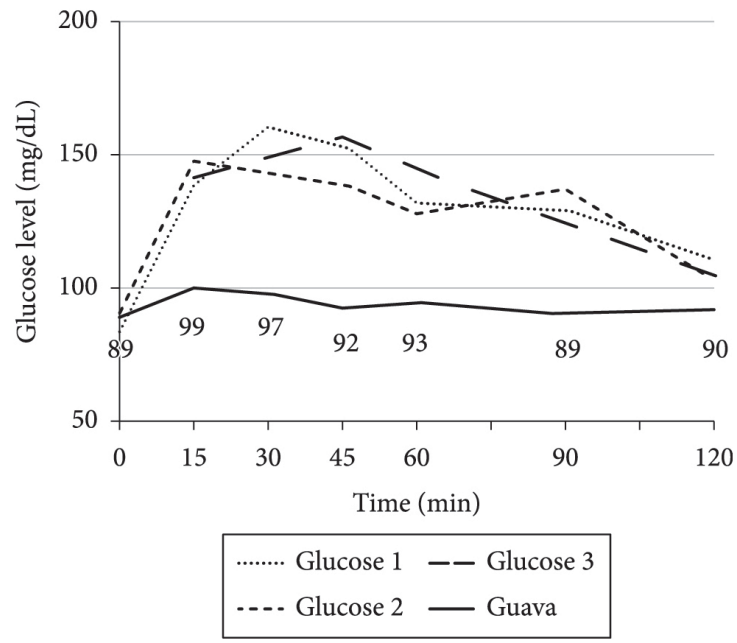

Figure 5. Average glucose levels based on the intake of guava by healthy subjects $(n=6)$.

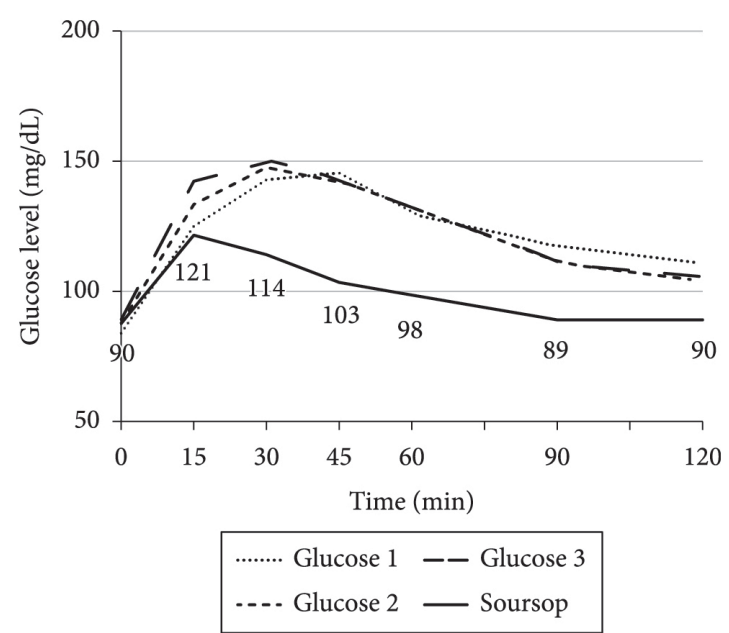

Figure 6. Average glucose levels based on the intake of soursop by healthy subjects $(n=6)$. 


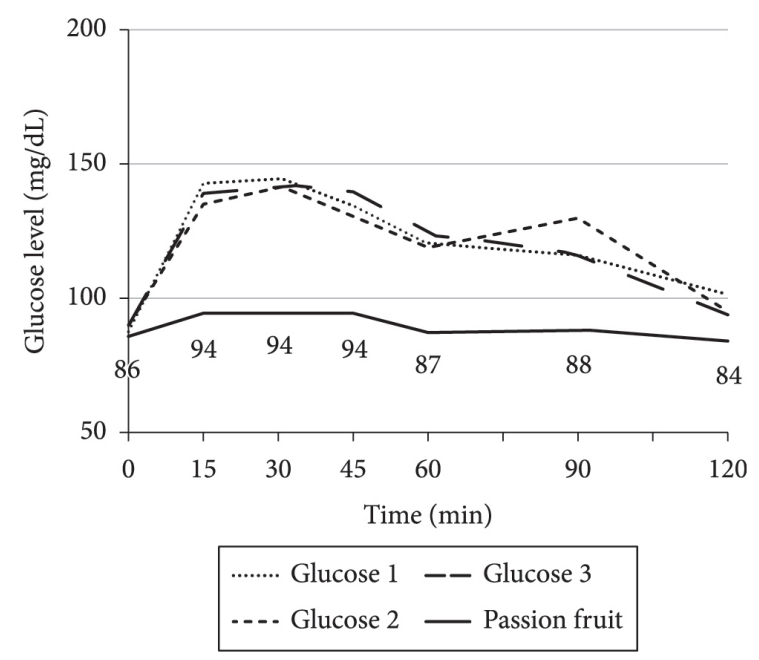

Figure 7. Average glucose levels based on the intake of passion fruit by healthy subjects $(n=6)$.

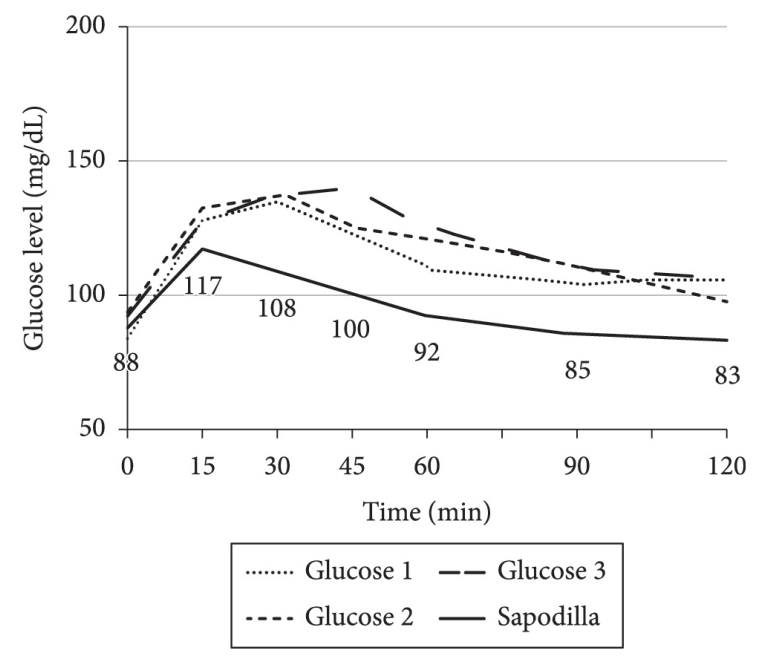

Figure 8. Average glucose levels based on the intake of sapodilla by healthy subjects $(n=6)$.

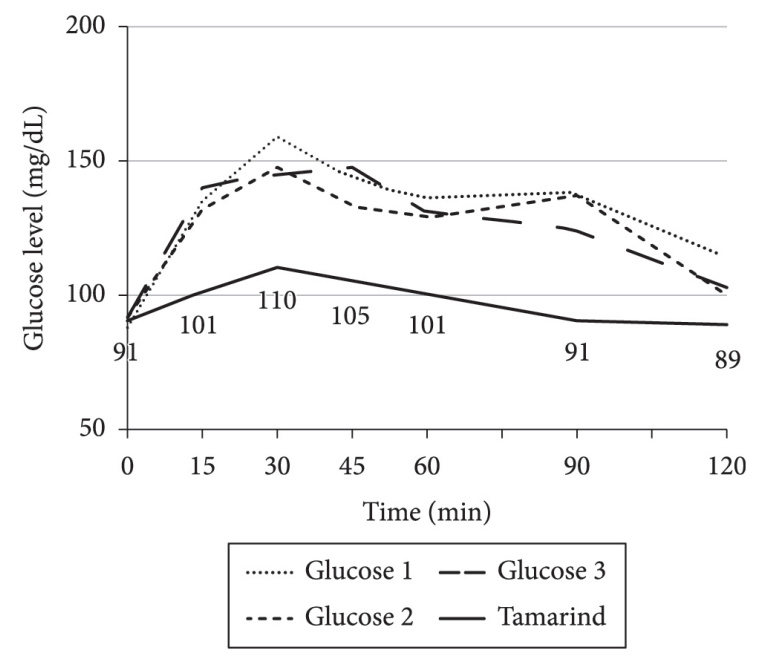

Figure 9. Average glucose levels based on the intake of tamarind by healthy subjects $(n=6)$. of their choice for the test, the amount of fruit was very high, especially in the case of the custard apple and coconut water.

The glycemic carbohydrate content required in the protocol used (Food and Agriculture Organization \& World Health Organization, 1998) is $50 \mathrm{~g}$, also reported in most studies as shown in recent investigations such as those of Augustin (2010), Bell (2011), Brand-Miller et al. (2009b), Kinnear (2010), Lan-Pidhainy \& Wolever (2011) and Uchiki et al. (2012). In order to minimize this problem, the use of $25 \mathrm{~g}$ of carbohydrate glucose has been proposed (Brand-Miller et al., 2009a), but this practice is still under debate.

Low and moderate glycemic indexes were found in the fruits tested (Table 3). However, the glycemic load for portions considered healthy (Brasil, 2006; Instituto Brasileiro de Geografia e Estatística, 2011; Pacheco, 2006) was considered as low for all fruits. Despite frequent consumption in Brazil, some fruits are considered seasonal, as they are available in greater quantity at specific times of the year. According to the "Brazilian Regional Food" (Brasil, 2002), many of the fruits investigated are found throughout the year, such as coconut (from which coconut water is extracted) and passion fruit. Aside from cashew, the others are also available most of the year, but they can be easily found in certain periods of the year: hog plum is most commonly found from December to June, soursop between January and March and guava from April to June and November to January. Only cashew is found almost exclusively from July to December.

The literature has highlighted the effect of fibers on the glycemic response, especially soluble fibers (Hettiaratchi et al., 2011; Menezes et al., 2009; Mira et al., 2009). Among the fruits mentioned, the fiber isolated from passion fruit has been identified as having hypoglycemic effects (Salgado et al., 2010, Zeraik et al., 2010), which was also observed in the present study, where the GI of this fruit was one of the lowest among those evaluated.

In addition to soluble fibers, studies available in the literature have discussed other components that can affect glycemic responses, for example, acidity, which causes delayed gastric emptying, resulting in a slower rate of digestion with subsequent reduction of the glycemic response (Brand-Miller et al., 2014). It is therefore likely that the acidity present in many of the fruits evaluated contributed to the findings of the present study (Brand-Miller et al., 2003; Novotni et al., 2011; Brand-Miller et al., 2014).

Despite the detailed discussions about the glycemic peaks above, the glycemic index of the fruits evaluated suggest beneficial health effects since most of them had low GI (77.8\%), two had moderate GI (coconut water and custard apple), and none of them had high GI. GL was low for all fruits. Regarding the recommendations that both GI and GL should be low, (Salehi et al., 2012; Egan et al., 2011), dietary restriction of coconut water and custard apple intake is advised. However, with regard to cashew (Figure 4), although its GI and GL are low, the initial glycemic peak triggered can be harmful, especially for people who have high fasting glucose level, such as obese patients who have metabolic syndrome and diabetic patients (Brand-Miller et al., 2009a). Gibson et al. (2011) also found variations in the glucose level peaks of foods belonging to the same food group. 
Table 3. Glycemic Index (GI) and glycemic load (GL) of the fruits evaluated and their classification.

\begin{tabular}{|c|c|c|c|c|}
\hline FRUIT & GI & CLASSIFICATION $^{*}$ & $\mathrm{GL}^{* *}$ & CLASSIFICATION $^{* * *}$ \\
\hline $\begin{array}{l}\text { Coconut } \\
\text { Water }\end{array}$ & $67 \pm 18.9$ & Moderate & $7 \pm 2.0$ & Low \\
\hline $\begin{array}{l}\text { Custard } \\
\text { Apple }\end{array}$ & $59 \pm 21.1$ & Moderate & $4 \pm 1.5$ & Low \\
\hline $\begin{array}{l}\text { Hogs } \\
\text { Plum }\end{array}$ & $24 \pm 17.8$ & Low & $2 \pm 1.6$ & Low \\
\hline Cashew & $45 \pm 12.2$ & Low & $7 \pm 1.8$ & Low \\
\hline Guava & $12 \pm 11.3$ & Low & $1 \pm 1.3$ & Low \\
\hline Soursop & $32 \pm 19.1$ & Low & $3 \pm 1.8$ & Low \\
\hline $\begin{array}{l}\text { Passion } \\
\text { fruit }\end{array}$ & $16 \pm 11.5$ & Low & $3 \pm 2.2$ & Low \\
\hline Sapodilla & $37 \pm 27.9$ & Low & $4 \pm 3.1$ & Low \\
\hline Tamarind & $23 \pm 13.9$ & Low & $6 \pm 3.3$ & Low \\
\hline \multicolumn{5}{|c|}{$\begin{array}{l}* \text { According to Brand-Miller et al. (2003). }{ }^{* *} \text { Recommended amount according to } \\
\text { the Food Guide for the Brazilian population (2006), Pacheco (2006), with standard } \\
\text { caloric equivalent to that in the Food Guide for the Brazilian population (2006) and the } \\
\text { Consumer Expenditure Survey (Instituto Brasileiro de Geografia e Estatística, 2011). } \\
* * * \text { According to Burani (2006). }\end{array}$} \\
\hline
\end{tabular}

According to Brand-Miller et al. (2009b), the glycemic curve should not be evaluated only in terms of calculation of the area under the curve (which leads to the determination of GI). The reason is that it is likely that the carbohydrates in some foods cause a sharp peak in the glycemic curve. However, these peaks can quickly disappear so that a value lower than the reference value can be obtained when performing the calculation of the area under the curve.

Still according to these authors, postprandial glucose peaks contribute to the development of chronic diseases, particularly atherosclerosis, and are an independent risk factor for cardiovascular disease. Even within the normal range, blood glucose peaks after meals may act directly to increase oxidative stress and inflammatory response (Brand-Miller et al., 2009a). However, this information has not been addressed in the International Tables for food GI.

According to the dietary restriction recommendations, aspects such as quantity, variety, and frequency of consumption should be taken into consideration. Since coconut water and custard apples have moderate GI, the intake of these fruits in quantities greater than recommended, the GC may also increase to moderate or even high levels. The same can occur if excessive amounts of low-GI fruits are consumed. The issue of quantity should be addressed individually considering people in general or those receiving treatment.

In general, guidelines such as the Dietary Guidelines for Americans (U.S. Department of Agriculture, 2010), recommend a daily intake of three servings of fruit. If a person consumes three servings of one fruit, the risk of inadequacy increases, underscoring the need for daily intake to be varied.

The issue of frequency becomes relevant because foods with moderate or high GI and/or GC may not be associated with health risks if consumed occasionally by healthy individuals, but it may worsen glycemic control in patients with chronic diseases such as diabetes mellitus. In Brazil, empirically, it has been observed in health services that there is an excessive intake of certain fruits during periods of greater availability, with subsequent reports of altered glucose levels in certain populations during these periods. It is important that seasonal consumption be investigated and quantified in order to be sure of the real impact of such consumption on health.

It cannot be omitted that the dietary analysis that uses GI and GL is still controversial as to the indications and importance. Some systematic reviews and revisions (Esfahani et al., 2009; Gnagnarella et al., 2008; Mente et al., 2009) demonstrate the value of using these indicators, but others do not show this relevance (Dong \& Qin, 2011; Esfahani et al., 2011; Mulholland et al., 2008, 2009). There is still a long way to go for researchers regarding this issue to ensure that GI and GL are quantified and addressed in studies on consumption and dietary prescription aimed at promoting health and preventing diseases.

\section{Conclusions}

Most of the Brazilian fruits evaluated have low-glycemic index and low glycemic load and can be consumed safely following the dietary guidelines for quantity and variety. More effective control of coconut water, cashew and custard apple intake is recommended, specifically for patients with chronic diseases and poor glycemic control.

\section{References}

Almeida, M. M. B., Sousa, P. H. M., Fonseca, M. L., Magalhães, C. E. C., Lopes, M. F. G., \& Lemos, T. L. G. (2009). Avaliação de macro e microminerais em frutas tropicais cultivadas no nordeste brasileiro. Food Science and Technology, 29(3), 581-586. Retrieved from http://www.scielo.br/scielo.php?script=sci_arttext\&pid=S010120612009000300020\&lng=en\&nrm=iso

American Diabetes Association - ADA. (2013). Standards of Medical Care in Diabetes. Diabetes Care, 36(Suppl 1).

Augustin, L. S. A. (2010). The dietary glycemic index and its implications in cancer risk, insulin-like growth factors and oxidative stress $(\mathrm{PhD}$ thesis). Faculty of Graduate Studies, University of Guelph, Canada.

Balisteiro, D. M., Alezandro, M. R., \& Genovese, M. I. (2013). Characterization and effect of clarified araçá (Psidium guineenses Sw.) juice on postprandial glycemia in healthy subjects. Food Science and Technology, 33(Suppl 1), 66-74. http://dx.doi.org/10.1590/ S0101-20612013000500011.

Ballali, S., \& Lanciai, F. (2012). Functional food and diabetes: a natural way in diabetes prevention? International Journal of Food Sciences and Nutrition, 63(Suppl 1), 51-61. http://dx.doi.org/10.3109/0963 7486.2011.637487. PMid:22107597

Bell, S. J. (2011). Glycemic index for the management of chronic disease: why certain foods like raisin may be beneficial. The Open Nutrition Journal, 5, 7-12. http://dx.doi.org/10.2174/1874288201105010007.

Brand-Miller, J. C., Foster-Powell, K., \& Colagiuri, S. (2003). A nova revolução da glicose. Rio de Janeiro: Elsevier.

Brand-Miller, J. C., Foster-Powell, K., \& Atkinson, F. (2013). The low GI shopper's guide to GI values 2013: the authoritative source of glycemic index values for more than 1.200 foods. Philadelphia: Da Capo Press. 
Brand-Miller, J. C., Foster-Powell, K., \& Atkinson, F. (2014). The low GI shopper's guide to GI values 2014: the authoritative source of glycemic index values for more than 1.200 foods. Philadelphia: Da Capo Press.

Brand-Miller, J., McMillan-Price, J., Steinbeck, K., \& Caterson, I. (2009a). Dietary glycemic index: health implications. Journal of the American College of Nutrition, 28(Suppl 4), 446S-449S. http://dx.doi.org/10.1 080/07315724.2009.10718110. PMid:20234031

Brand-Miller, J. C., Stockmann, K., Atkinson, F., Petocz, P., \& Denyer, G. (2009b). Glycemic index, postprandial glycemia, and the shape of the curve in healthy subjects: analysis of a database of more than 1,000 foods. The American Journal of Clinical Nutrition, 89(1), 97105. http://dx.doi.org/10.3945/ajcn.2008.26354. PMid:19056599

Brasil, Ministério da Saúde, Secretaria de Atenção à Saúde. CoordenaçãoGeral da Política de Alimentação e Nutrição. (2002). Alimentos regionais brasileiros. Brasília: Ministério da Saúde. 140 p.

Brasil, Ministério da Saúde, Secretaria de Atenção à Saúde. CoordenaçãoGeral da Política de Alimentação e Nutrição. (2006). Guia alimentar para a população brasileira: promovendo a alimentação saudável. Brasília: Ministério da Saúde. 210 p.

Burani, J. (2006). Gushers and tricklers: practical use of the glycemic index, 22. Retrieved from http://www.eatgoodcarbs.com/glycemicindex-diabetes-presentations.html

Danone Vitapole/FAO. (2001). Glycaemic index and health: the quality of the evidence. Bandol: John Libbey Eurotext.

Dong, J. Y., \& Qin, L. Q. (2011). Dietary glycemic index, glycemic load, and risk of breast cancer: meta-analysis of prospective cohort studies. Breast Cancer Research and Treatment, 126(2), 287-294. http://dx.doi. org/10.1007/s10549-011-1343-3. PMid:21221764

Egan, N., Read, A., Riley, P., \& Atiomo, W. (2011). Evaluating compliance to a low glycaemic index (GI) diet in women with polycystic ovary syndrome (PCOS). Biomed Research Notes, 4(1), 53. http://dx.doi. org/10.1186/1756-0500-4-53.

Esfahani, A., Wong, J. M., Mirrahimi, A., Srichaikul, K., Jenkins, D. J., \& Kendall, C. W. (2009). The glycemic index: physiological significance. Journal of the American College of Nutrition, 28 Suppl., 439S-445S. http://dx.doi.org/10.1080/07315724.2009.10718109. PMid:20234030

Esfahani, A., Wong, J. M., Mirrahimi, A., Villa, C. R., \& Kendall, C. W. (2011). The application of the glycemic index and glycemic load in weight loss: A review of the clinical evidence. International Union of Biochemistry and Molecular Biology Life, 63(1), 7-13. http://dx.doi. org/10.1002/iub.418. PMid:21280171

Food and Agriculture Organization - FAO, World Health Organization - WHO. (1998). Carbohydrates in human nutrition. Geneva.

Gibson, N., Schonfeldt, H. C., \& Pretorius, B. (2011). Development of a rapid assessment method for the prediction of the glycemic index. Journal of Food Composition and Analysis, 24(4-5), 750-754. http:// dx.doi.org/10.1016/j.jfca.2011.01.005.

Gnagnarella, P., Gandini, S., La Vecchia, C., \& Maisonneuve, P. (2008). Glycemic index, glycemic load, and cancer risk: a meta-analysis. The American Journal of Clinical Nutrition, 87(6), 1793-1801. PMid:18541570.

Hettiaratchi, U. P. K., Ekanayake, S., \& Welihinda, J. (2011). Chemical compositions and glycemic responses to banana varieties. International Journal of Food Sciences and Nutrition, 62(4), 307-309. http://dx.doi. org/10.3109/09637486.2010.537254. PMid:21250902

Instituto Brasileiro de Geografia e Estatística - IBGE. (2011). Pesquisa de orçamentos familiares 2008-2009: tabela de medidas referidas para os alimentos consumidos no Brasil. Rio de Janeiro.

Jenkins, D. J., Srichaikul, K., Kendall, C. W., Sievenpiper, J. L., Abdulnour, S., Mirrahimi, A., Meneses, C., Nishi, S., He, X., Lee, S., So, Y. T.,
Esfahani, A., Mitchell, S., Parker, T. L., Vidgen, E., Josse, R. G., \& Leiter, L. A. (2011). The relation of low glycaemic index fruit consumption to glycaemic control and risk factors for coronary heart disease in type 2 diabetes. Diabetologia, 54(2), 271-279. http:// dx.doi.org/10.1007/s00125-010-1927-1. PMid:20978741

Jenkins, D. J., Wolever, T. M., Taylor, R. H., Barker, H., Fielden, H., Baldwin, J. M., Bowling, A. C., Newman, H. C., Jenkins, A. L., \& Goff, D. V. (1981). Glycemic index of foods: a physiological basis for carbohydrate exchange. The American Journal of Clinical Nutrition, 34(3), 362-366. PMid:6259925.

Kinnear, T. (2010). Interaction between the effects of preparation method and variety on the glycemic index of novel potato varieties ( $\mathrm{PhD}$ thesis). Department of Nutritional Sciences, University of Toronto, Canada.

Lan-Pidhainy, X., \& Wolever, T. M. S. (2011). Are the glycemic and insulinemic index values of carbohydrate foods similar in healthy control, hyperinsulinemic and type 2 diabetic patients? European Journal of Clinical Nutrition, 65(6), 727-734. http://dx.doi.org/10.1038/ ejcn.2011.28. PMid:21427735

Mahan, L. K., \& Escott-Stump, S. (2010). Krause alimentos, nutrição e dietoterapia. 12. ed. São Paulo: Roca.

Menezes, E. W., Giuntini, E. B., Dan, M. C. T., \& Lajolo, F. M. (2009). New information on carbohydrates in the Brazilian Food Composition Database. Journal of Food Composition and Analysis, 22(5), 446-452. http://dx.doi.org/10.1016/j.jfca.2009.02.001.

Mente, A., Koning, L., Shannon, H. S., \& Anand, S. S. (2009). A systematic review of the evidence supporting a causal link between dietary factors and coronary heart disease. Archives of Internal Medicine, 169(7), 659-669. http://dx.doi.org/10.1001/archinternmed.2009.38. PMid:19364995

Mira, G. S., Graf, H., \& Candido, L. M. B. (2009). Visão retrospectiva em fibras alimentares com ênfase em beta-glucanas no tratamento do diabetes. Brazilian Journal of Pharmaceutical Sciences, 45(1), 11-20. http://dx.doi.org/10.1590/S1984-82502009000100003.

Mulholland, H. G., Murray, L. J., Cardwell, C. R., \& Cantwell, M. M. (2008). Dietary glycaemic index, glycaemic load and breast cancer risk: a systematic review and meta-analysis. British Journal of Cancer, 99(7), 1170-1175. http://dx.doi.org/10.1038/sj.bjc.6604618. PMid:18728653

Mulholland, H. G., Murray, L. J., Cardwell, C. R., \& Cantwell, M. M. (2009). Glycemic index, glycemic load, and risk of digestive tract neoplasms: a systematic review and meta-analysis. The American Journal of Clinical Nutrition, 89(2), 568-576. http://dx.doi.org/10.3945/ ajcn.2008.26823. PMid:19088152

Novotni, D., Curić, D., Bituh, M., Colić Barić, I., Skevin, D., \& Cukelj, N. (2011). Glycemic index and phenolics of partially-baked frozen bread with sourdough. International Journal of Food Sciences and Nutrition, 62(1), 26-33. http://dx.doi.org/10.3109/09637486.2010. 506432. PMid:20715901

Pacheco, M. (2006). Tabela de equivalentes, medidas caseiras e composição química dos alimentos. Rio de Janeiro: Rubio.

Passos, T. U. (2012). Consumo alimentar cearense: índice glicêmico e carga glicêmica de alimentos regionais e impacto potencial no risco de doenças crônicas não transmissíveis (Dissertação de mestrado). Universidade Estadual do Ceará, Fortaleza.

Salehi, M., Yousefinejad, A., \& Pishdad, G. (2012). The effect of a diet education with six iso-caloric meals on the body weight and blood glucose of diabetes type 2 patients. Food Science and Technology, 32(2), 329-333. Retrieved from http://www.scielo.br/ scielo.php?script=sci_arttext\&pid=S0101-20612012000200019\&ln $\mathrm{g}=\mathrm{en} \& \mathrm{nrm}=$ iso 
Salgado, J. M., Bombarde, T. A. D., Mansi, D. N., Piedade, S. M. S., \& Meletti, L. M. M. (2010). Effects of different concentrations of passion fruit peel (Passiflora edulis) on the glicemic control in diabetic rat. Food Science and Technology, 30(3), 784-789. Retrieved from: http://www.scielo.br/scielo.php?script=sci_arttext\&pid=S010120612010000300034\&lng=en\&nrm=iso

The University of Sydney, Glycemic Index. (2001). Sydney University Glycemic Index Research Service (SUGIRS). Retrieved from http:// www.glycemicindex.com

U.S. Department of Agriculture, U.S. Department of Health and Human Services. (2010). Dietary Guidelines for Americans. Washington.

Uchiki, T., Weikel, K. A., Jiao, W., Shang, F., Caceres, A., Pawlak, D., Handa, J. T., Brownlee, M., Nagaraj, R., \& Taylor, A. (2012). Glycation-altered proteolysis as a pathobiologic mechanism that links dietary glycemic index, aging, and age-related disease (in nondiabetics). Aging Cell, 11(1), 1-13. http://dx.doi.org/10.1111/j.1474-9726.2011.00752.x. PMid:21967227
Universidade Estadual de Campinas - UNICAMP, Núcleo de Estudos e Pesquisas em Alimentação. (2006). Tabela Brasileira de Composição de Alimentos (TACO). Versão II (2. ed.). Campinas.

Wolever, T. M. S. (2004). Carbohidratos de digestión lenta: beneficios de una alimentación con bajo índice glicémico. Mexico: Alimentariaonline. Retrieved from http://www.alimentariaonline.com/apadmin/img/ upload/MA003_CHOdiglentaglicemiaWSF.pdf

Wolever, T. M., Vorster, H. H., Björck, I., Brand-Miller, J., Brighenti, F., Mann, J. I., Ramdath, D. D., Granfeldt, Y., Holt, S., Perry, T. L., Venter, C., \& Xiaomei W. (2003). Determination of the glycaemic index of foods: interlaboratory study. European Journal of Clinical Nutrition, 57(3), 475-482. http://dx.doi.org/10.1038/sj.ejcn.1601551. PMid:12627186

Zeraik, M. L., Pereira, C. A. M., Zuin, V. G., \& Yariwake, J. H. (2010). Maracujá: um alimento funcional? Revista Brasileira de Farmacognosia, 20(3), 459-471. http://dx.doi.org/10.1590/S0102-695X2010000300026. 